\title{
To connect or not to connect? Modelling the optimal degree of centralisation for wastewater infrastructures
}

\author{
Eggimann Sven ${ }^{1,2^{*}}$, Truffer Bernhard ${ }^{1,3}$, Maurer $\operatorname{Max}^{1,2}$ \\ 1 Eawag, Swiss Federal Institute of Aquatic Science and Technology, 8600 Dübendorf, Switzerland. \\ 2 Institute of Civil, Environmental and Geomatic Engineering, ETH Zürich, 8093 Zurich, Switzerland. \\ 3 Faculty of Geosciences, Utrecht University, Heidelberglaan 2, NL-3584 CS Utrecht, The Netherlands.
}

\author{
Keywords \\ Sustainable Network Infrastructure Planning \\ Geographic Information System \\ Sewer Modelling \\ Algorithmic Network Generation \\ Wastewater Infrastructure \\ Degree of Centralisation
}

\section{Abstract}

The strong reliance of most utility services on centralised network infrastructures is becoming increasingly challenged by new technological advances in decentralised alternatives. However, not enough effort has been made to develop planning tools designed to address the implications of these new opportunities and to determine the optimal degree of centralisation of these infrastructures. We introduce a planning tool for sustainable network infrastructure planning (SNIP), a two-step techno-economic heuristic modelling approach based on shortest path-finding and hierarchical-agglomerative clustering algorithms to determine the optimal degree of centralisation in the field of wastewater management. This SNIP model optimises the distribution of wastewater treatment plants and the sewer network outlay relative to several cost and sewer-design parameters. Moreover, it allows us to construct alternative optimal wastewater system designs taking into account topography, economies of scale as well as the full size range of wastewater treatment plants. We quantify and confirm that the optimal degree of centralisation decreases with increasing terrain complexity and settlement dispersion while showing that the effect of the latter exceeds that of topography. Case study results for a Swiss community indicate that the calculated optimal degree of centralisation is substantially lower than the current level. 


\section{Introduction}

\subsection{Sustainable Network Infrastructure Planning (SNIP)}

T $\mathrm{n}$ the last two centuries, many physical net1 work infrastructures of various types have been built worldwide. ${ }^{1}$ This implementation of extensive networks was accompanied by a widely shared conviction in expert and policy circles that technological centralisation would generally lead to superior solutions ('Graham and Marvin 2001). As a consequence, an "expand and upgrade" philosophy became predominant (Moss 2001). This approach leads to biased economic incentives because actors tend to base their decisions on economies of scale in the cost of a centralised wastewater plant, while neglecting the economies of scale at the level of the entire network, which are, as a rule, much more difficult to assess (Maurer et al. 2012). As a consequence, centralisation always seems to be the preferred solution for decision makers. More recently, however, new context conditions have led to this generally received wisdom being questioned (Marlow et al. 2013). Reasons for questioning the sustainability of the centralised approach include shrinking public budgets and subsidies as well as the massive maintenance and restoration costs of centralised systems (Maurer and Herlyn 2006). Furthermore, new technological advances such as remotely operating measuring devices and membrane technology challenge the centralised approach as they increasingly help decentralised technology to be considered as a fully functional substitute for centralised infrastructures ( $(\mathrm{Li}-$ bralato et al. 2012).

We assume that decentralised alternatives can already, or will soon be able to, deliver utility services of comparable quality, which means that the superiority of the centralised paradigm can no longer be taken for granted, and ques- tions about the optimal degree of centralisation (ODC) need to be addressed. A shift to a decentralised approach has broad economic, technical and environmental implications (e.g. environmental risks) which need to be addressed elsewhere in the literature (inter alia Libralato et al. 2012, Poustie et al. 2014). In the present paper, we introduce the Sustainable Network Infrastructure Planning (SNIP) approach, which consists of a single objective cost-optimisation algorithm designed to determine the ODC for wastewater systems. We start from the assumption that we do not have to choose either a purely centralised or a purely decentralised service structure for a given region but that the optimum configuration will generally be defined by some sort of hybrid constellation (Poustie et al. 2014, Sapkota et al. 2015), also referred to as a distributed wastewater infrastructure (inter alia 'T chobanoglous and Lev-' 'erenz 2013). We define a system as being increasingly centralised as more elements are linked to it and interconnected (for an elaborate definition, see Section. 3.1). As a result, we are able to determine to what degree economies of scale in wastewater treatment drive infrastructural centralisation, or whether distributed systems may result in lower total system costs.

Finding the ODC is methodologically challenging because of the large number of system alternatives that have to be considered. Very recently, scholars have started to tackle these complexities in integrated strategic planning by means of exploratory modelling techniques (Urich and Rauch 2014). Still, only few tools (for exceptions see inter alia 'Zeferino et al. 2010, Sitzenfrei et al. 2013, Urich and Rauch 2014) are currently available to determine optimal combinations of these alternatives, especially if we consider real-world data. The main focus of the present paper is to introduce the SNIP methodology and apply it to the case of wastewater

1 Examples can be found in the field of transportation (Rodrigue et al. 2013), in heating and energy systems (Hughes 1983, 'Gochenour 2001, 'Hawkey 2012) as well as drinking and wastewater systems (Lofrano and Brown 2010, 'Geels 2006). 
management. These systems are highly suitable infrastructures for studying ODC. The sector has developed a strongly centralised paradigm in many industrialised countries, which has frequently led to connection rates above 95\%. However, fully functional decentralised alternatives have emerged only recently and their longer-term contribution to wastewater treatment is still unknown. Finally, centralised infrastructures are coming to the end of an investment cycle, and many communities in the industrialised world have to consider whether and how they want to reinvest in their existing systems (OECD 2006/7, Urban Land Institute and Ernst\&Young 2007). This question is also relevant for other network infrastructures such as electricity, heating or water supplies.

The current SNIP approach comprises a single-objective framework focussing exclusively on the minimisation of total system costs (compare inter alia Weber et al. 2007, Sapkota et al. 2013i). SNIP could very well be expanded in a multi-objective approach, where a broader set of objectives could be included in the cost or objective function. However, many of the key objectives, such as performance, failure frequency or environmental effects of distributed wastewater systems are not trivial to assess and their inclusion in the text would greatly exceed the scope of this paper. Our approach limits itself to determining the ODC only from a cost efficiency point of view.

The manuscript is structured as follows: in the remainder of Section we further specify the state of the literature on determining ODCs for network infrastructures. In Section 2 we present the SNIP model in detail. Sections and 4 present real-world and virtual case studies to illustrate the performance of the approach. Section ' 5 ' concludes this study specifying the further development steps of the methodology.

\subsection{Location Problem in the Field of Wastewater Management}

7 inding the ODC for wastewater infra$\perp$ structures involve questions of optimal geographical placement, sizing and number of facilities and can be seen as a location model. Different types of location models exist, whereas a model designed to minimize total facility and transportation costs is defined as a fixed-charge location problem (Current et al. 2002). ${ }^{2}$ For an application in wastewater management, we define the facilities as wastewater treatment plants (WWTP) and understand sewer-related infrastructures as a means of transporting wastewater. It is extremely difficult to solve these kinds of optimum location models because they are NP-complete. The most important aspect of $\mathrm{NP}$-complete problems is that we cannot solve them deterministically in polynomial time ('Gar-' ey and Johnson 1979). Therefore finding solutions results in a high computational burden for any application that involves realistic data sets. One way to solve these problems is by looking for approximate solutions with the aid of heuristics. Given the complexity of the problem of determining the ODC, finding approximate solutions with the aid of heuristics is already a big step forward. Approximate solutions may still be very useful for decision makers at those points in time when strategic decisions must be made.

Compared to other network infrastructures, the management of wastewater has some specific characteristics:

- There exists a long-known economic trade-off between installing wastewater treatment plants and extending the sewer network (inter alia Converse 1972). The literature suggests high economies of scale in the treatment of wastewater but a tendency for diseconomies of scale in the construction of sewer networks. This

2 Fixed costs are assumed for locating a facility at a candidate site. For a detailed problem formulation, see Daskin (1995). 
trade-off is further aggravated as typically more than $80 \%$ of the investment costs have to be spent on sewer infrastructures (Maurer et al. 2006). These cost calculations are based on typical infrastructure lifetimes of 25 years for WWTP and 80 years for sewers.

- Water is quite bulky and heavy per source (household) and wastewater generation rates vary depending on the geographical context (UNEP 2015). As a consequence, topography has a strong influence on network costs, especially as gravity-driven sewers are the preferred type of transportation.

- Sewers are usually considered to have a relatively high average life-span of about 80 years compared to approximately 25 years for large scale WWTP. Larger uncertainties are attributed to the life expectancy of smaller WWTP.

\subsection{Critical Literature Review}

$\mathrm{D}$ espite the fact that the problem of finding the ODC has been raised repeatedly (inter alia by Downing 1969, 'Gawad and Butter 1995, 'Ambros 1996) in various technological fields, only little research has actually been conducted into this topic. However, we notice that researchers are increasingly focussing on the transition to more decentralised systems (inter alia 'Sitzenfrei' and Rauch 2014, Bach et al. 2013) and the question of the sustainability of the degree of centralisation (inter alia Poustie et al. 2014).

The issue of the optimal degree of centralisation is crucial for many network based infrastructures. Therefore, before focussing on the literature in the field of wastewater we will take a look at the available literature in other fields, especially that of electricity infrastructures. Although a comparison with other infrastructures such as water distribution systems (inter alia $\mathrm{Oss}^{-1}$ itfeld 2015) would be interesting, we believe that the link to the energy literature is especially fruitful given its extensive use of heuristic approaches.

Recently, discussions about centralised versus decentralised technologies have taken place in the fields of electricity network infrastructures (Kocaman et al. 2012, Levin and Thomas 2012, Sanoh et al. 2012, Parshall et al. 2009, Deichmann et al. 2011), hydrogen distribution networks (Johnson et al. 2008, 'Stiller et al. 2010, Baufumé et al. 2013) and district heating (Möller and Lund 2010, Gils et al. 2013, Nielsen and Möller 2013). Different types of methodological approaches such as mixed integer programming, branch and bound methods or heuristic algorithms are used to determine the optimal outlays for these infrastructures (Kocaman et al. 2012).

Zvoleffet al. (2009)' use a heuristic network algorithm to access the impact of geography on infrastructure costs and suggest a linkage between the increasing distance per building connection (marginal distance) and the increasing percentage of the connected population. The marginal distance indicates when connection expenses become unreasonable, thus making a decentralised option economically preferable. Levin and Thomas (2012) use similar techniques and create a least-cost transmission network for connecting a given fraction of the population. Even though the authors include decentralised technologies, they do not consider multiple disaggregated networks. In contrast, 'Sanoh et al. (2012)' and Parshall et al. (2009) start from a pre-existing network and try to determine whether specific still-unconnected nodes are better served with a decentralised option or a network extension.

The most comprehensive approach so far considers multiple transformer stations and network sizes to determine the optimal infrastructure outlay (Kocaman et al. 2012). The authors use an agglomerative hierarchical clustering method to find optimal locations of transform- 
ers and minimize overall grid costs. This approach consequently results in networks of various sizes and thus produces hybrid solutions. Its limiting factor is the large computation burden when the restrictions are more complex or the algorithm is not based on straight-line distances alone.

For wastewater management, network infrastructures (simulated or pre-existing) are also needed to estimate centralised and decentralised costs. For a recent overview of integrated urban water modelling techniques we refer to Bach et al. (2014). Even though a number of innovative methods are available to design and automatically generate different kinds of network infrastructure such as drinking water (inter alia Urich et al. 2010) or sewer networks (inter alia Blumensaat et al.: 2012, Bach et al. 2014), ${ }^{3}$ they are not used to address the question of the ODC. With the few exceptions listed below, no geographically explicit analysis of where to treat wastewater in a more decentralised or centralised manner has yet been systematically elaborated. Brand and Ostfeld (2011) point out the general lack of optimisation models incorporating all the most basic system components such as sewers, WWTP and pumps at the same time, and Sitzenfrei et al. (2013)' observe that tedious handling and processing of explicit geographic data is required to generate cost estimates for centralised infrastructures.

Nevertheless, there are important exceptions in the literature which cover the optimisation of wastewater infrastructure: 'Schiller (2010)i uses GIS to determine where to start a transition towards decentralised wastewater management systems from existing sewer networks in case of a shrinking population. Zeferino et al. (2010) consider hybrid solutions and use simulated annealing to determine different optimal system configurations in a multi-objective framework. Leitão et al. (2005) compare a drop and a add algorithm to solve a location model at regional level.

\subsection{Original contribution of the presented SNIP model}

A brief overview of the literature on heuristic network optimisation shows that only few approaches consider hybrid constellations. In combination with sewer modelling, we can deduce four main shortcomings in the literature that the SNIP approach takes as a starting point:

- Even though a number of innovative methods exist to model sewer systems, only few of them explicitly address the ODC.

- Most optimisation approaches apply a dichotomic perspective, whereas real cases require hybrid constellations such as distributed wastewater systems with self-contained wastewater networks for any given landscape.

- The optimisation rule in most ODC models is limited to investment costs and straight-line distance calculations on flat terrain. Further costs are calculated independently of the position in the network and (dis-)economies of scale are not considered.

- A common limitation of all the approaches to network infrastructures (wastewater or other networks) mentioned so far is that they do not consider changes occurring in the physical network properties as the size of the network changes.

3 Two sewer modelling approaches can be distinguished, namely those that model actual case-specific sewer systems and those that estimate the material stock of the sewer infrastructures with the aid of virtual network layouts. As we focus on the optimisation process, and the detailed network design is of secondary interest, we refer to Maurer et al. (2012), for an overview. 


\section{Model Description}

\subsection{Optimisation Function}

7 he SNIP algorithm is based on cost and 1 sewer-design assumptions and aims to determine the ODC by minimizing the overall system costs $(C)$ of a wastewater system by considering the costs of WWTP of varying sizes, pumping and sewer costs. We solve the cost objective function (Eq. 1) by numerical computation.

$$
\operatorname{Min} C\left(N_{W W T P,}, V_{W W T P}, l, d, V_{P U M P}, H\right)
$$

where the total system costs $C$ depend on the number of WWTP $\left(N_{\text {WWTP }}\right)$, the wastewater volume treated per WWTP $\left(V_{\text {WWTP }}\right)$, the sewer network length ( $l$ ), the sewer diameters $(d)$, the pumped volume $\left(V_{P U M P}\right)$ and the pump head at the duty point $(H)$.

In each iteration step $i$, the values of the variables are changed and the new cost function $C_{i+1}$ is generated and compared to $C_{i}$. The iteration stops when $C_{i+1} \geq C_{i}$ (see Fig. 1).

\subsection{SNIP Algorithm Modules}

7 he SNIP algorithm is partitioned into 1 two main consecutive functional modules, namely the expansion module (EM) and the merging module (MM) (Fig. 1). The EM is responsible for calculating a first system outlay whereas the MM improves overall cost savings by merging or agglomerating WWTP.

In a first step, the EM determines an initial set of WWTP and sewers which are defined from the bottom-up with shortest path-finding algorithms. In a second step, the MM looks for further cost savings by checking the potential merging of WWTP by means of heuristic agglomerative hierarchical clustering (Kaufman and Rousseeuw 2005).

Both modules execute sub-modules: the path-finding module (PFM) determines the path along which sewers are constructed. The system option module (SOM) identifies potential system options and the cost module (CM) determines the overall costs of each option. The algorithm terminates when no further cost decreases can be achieved by merging any WWTP.

The two main modules use greedy algorithms: these are characterized by the assumption that selecting the best-looking choice at each iterating step of the optimization procedure will yield an optimal global solution ('Cormen et al. 2009). The assumption that local optimal choices result in a globally optimal solution is not generally true, even though it may be valid for many problems (Cormen et al. 2009). Given the problem complexity, finding reasonably approximate solutions is the only way forward given the restrictions of computation time. As decisions made in the EM can be altered in the MM, SNIP is neither an add nor a drop algorithm (Daskin 1995), but a mixture of both.

In the following sections, we describe the algorithm workflow with all sub-processes in more detail.

\subsubsection{Expansion Module (EM)}

The EM is based on 'Prim's algorithm (1957), which is well-known and widely applied in infrastructure planning and graph theory. It represents the sewer network as edges and houses, and WWTP as nodes. It then calculates a graph which connects all nodes with minimal edge weights to produce a minimum spanning tree (MST). Edge weights are generally derived from straight-line distances between nodes, but they can represent any metric such as time or costs. Prim's algorithm thus allows a least-cost network connecting all nodes to be found.

The use of gravity-driven sewer lines means that the actual path between two nodes may not be a straight line. So costs cannot be derived linearly from straight-line distances, and this makes 
it a complex task to attribute real costs to each edge. Thus sewer costs may depend on the direction of flow, the trench depth and any height differences encountered. More sophisticated methods are consequently needed for estimating costs.

We choose the following five-step approach to build a minimum network representing sewers and WWTP in a simplified manner (cf. Fig. 1):

Step I: We first select a starting node (household). ${ }^{4}$ We then determine the minimum connection costs between this node and all still un-connected nodes. As the distance is important, the classical Prim-based approach of approximating connection costs between two nodes with straight-line distances seems plausible. Thus the assumption is made that the closest node is the best one for iteratively considering a network connection. In contrast to Prim's algorithm, we ask in each iteration whether a connection leads to cost minimisation, an approach which resembles the clustering idea of 'Zahn (1971)', who removes edges from a fully calculated MST.

Step II: The sewers between the two detected nodes from Step I are designed with the path-finding module. The PFM determines the path with the aid of the street network and a digital terrain model (DTM). The motivation to use the street network is the close linkage between the two networks that is often found (Blumensaat et al. 2012, Nielsen and Möller 2013). However, this assumption may not always be true, especially if the distance along the street network is significantly longer where no street exists.

Our algorithm first identifies the direct distance $d_{\text {direct }}$ between the two nodes from step

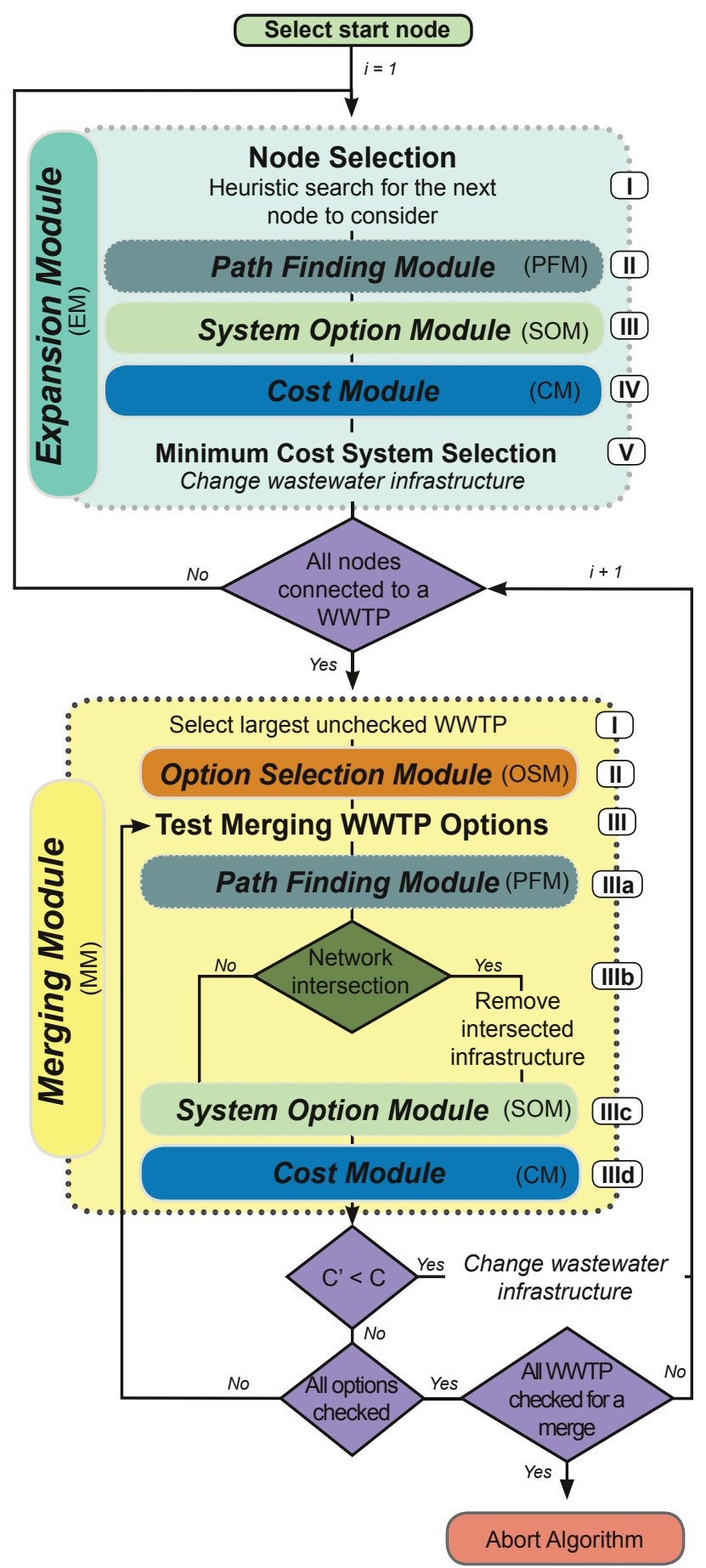

Figure 1: SNIP algorithm workflow. The EM calculates an initial network layout until all nodes have a sanitation solution, while the MM optimises the infrastructure layout generated by the EM.

I. The Dijkstra Algorithm (Dijkstra 1959) is applied to a street network to find the short-

4 Due to the heuristic nature of the algorithm, the result is dependent on the starting node. Therefore we recommend that the algorithm be run with different starting nodes even though our case study results indicate low effects (Appendix B). Due to the logic of the algorithm, it makes sense to start at a node which lies in an area of high node density. These areas offer a greater chance that the total system costs will decrease by connecting nodes. 
est distance between the next node to connect and the existing sewer network $\left(d_{\text {street }}\right)$. The decision as to which sewer path to take is based on the ratio fstreet between the direct distance $\left(d_{\text {direct }}\right)$ and the distance along the street (Eq. 2).

$$
f_{\text {street }}=\frac{d_{\text {street }}}{d_{\text {direct }}}
$$

We derive $f_{\text {street }}$ by comparing existing connection ratios in a given sewer network for an area of interest. So by changing this ratio, we can adapt the sewer design to local design practice. If $f_{\text {street }}$ is larger than the derived ratio, an alternative sewer path following the local topography is calculated with help of the $\mathrm{a}^{*}$ algorithm (Hart et al. 1968).

For the 3D path-finding methodology along the terrain, we build a graph from the raster-based DTM on which each centre raster point links all neighbouring cell centre points (queen neighbourhood) (Leitão et al. 2005). We derive the edge weights of the resulting graph from the height difference $\Delta h$ between the raster cells and a weighting factor $f_{\text {topo }}$ used to calculate a weighted distance $\mathrm{d}_{\mathrm{w}}$ (Eq. 3).

$$
\mathrm{d}_{\mathrm{w}}=\mathrm{d}_{\text {direct }}|\Delta \mathrm{h}|_{\text {topo }}^{\mathrm{f}_{\text {o }}}
$$

where $f_{\text {topo }}$ can be altered depending on how closely the sewers should follow the topography. More sophisticated methods, such as land data use, could be applied to determine the weighting on anisotropic surfaces (Yu et al. 2003). However, the weighting is not of primary interest in this paper and the only restriction is that sewers cannot cross raster cells of the DTM containing buildings.

Step III: After the sewer path has been determined, three system options are always identified with the System Option Module (SOM, explained in Section 2.2.2), namely an option without sewer expansion and two options with a sewer expansion in either direction. We use the term system option to describe one system configuration. As different system options are available for selection in each iteration, this allows a cost-optimised system to be selected locally.

Step IV: Operation costs and replacement costs are attributed to the design alternatives

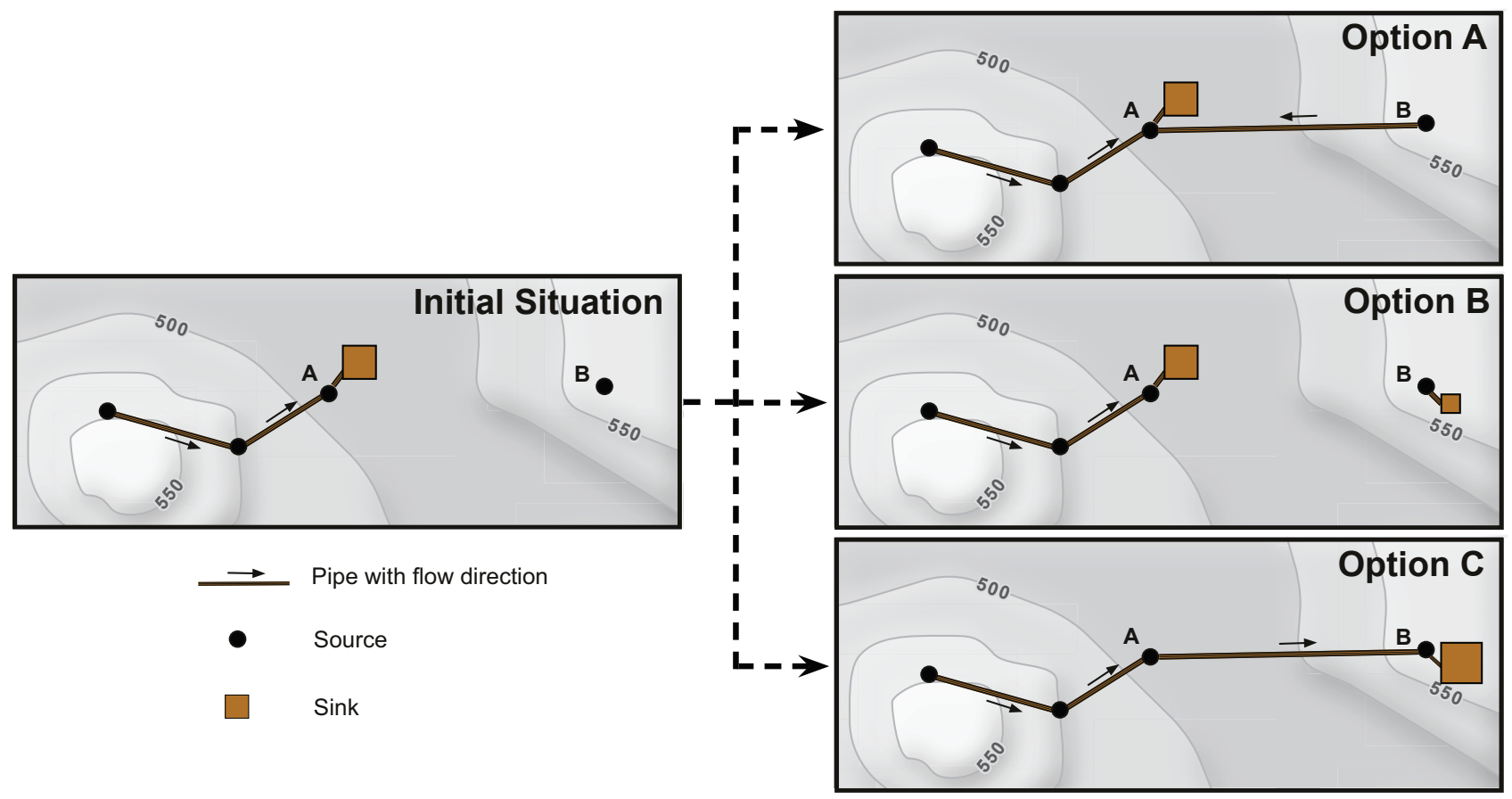

Figure 2: System design options (SOM module) for an exemplary initial situation. Options A and C show a network expansion in combination with a WWTP enlargement. In option B the network is not enlarged and a new WWTP is installed instead. 


\begin{tabular}{|c|c|c|c|c|c|}
\hline & \multirow[t]{2}{*}{ Symbol } & \multirow[t]{2}{*}{ Unit } & \multirow[t]{2}{*}{$\begin{array}{l}\text { Base scenario } \\
\text { value }\end{array}$} & \multicolumn{2}{|c|}{$\begin{array}{c}\text { Considered limits in } \\
\text { eFAST analysis }\end{array}$} \\
\hline & & & & Lower & Upper \\
\hline \multicolumn{6}{|l|}{ Design Parameter } \\
\hline Maximum trench depth & $\mathrm{T}_{\max }$ & $\mathrm{m}$ & 8 & 8 & 12 \\
\hline Minimum trench depth & $\mathrm{T}_{\min }$ & $\mathrm{m}$ & 0.25 & - & - \\
\hline Minimum slope & $f_{\text {minslope }}$ & $\%$ & 1 & 1 & 3 \\
\hline Sewer design factor & $f_{\text {street }}$ & - & 1.7 & 1 & 5 \\
\hline Sewer design factor & $f_{\text {topo }}$ & - & 1.4 & 1 & 2 \\
\hline Merging factor & $f_{\text {merge }}$ & - & 3 & 1 & 5 \\
\hline Wastewater production & $Q_{w w}$ & $\mathrm{~m}^{3} \mathrm{~d}^{-1}$ & 0.162 & 0.1 & 0.4 \\
\hline Strickler coefficient & $\mathrm{k}_{\mathrm{st}}$ & capita $^{-1}$ & 85 & & \\
\hline \multirow[t]{2}{*}{ Pipe diameter } & $\mathrm{d}$ & $\mathrm{m}^{1 / 3} \mathrm{~s}^{-1}$ & standard & & \\
\hline & & $\mathrm{m}$ & values & & \\
\hline \multicolumn{6}{|l|}{ Cost Parameter } \\
\hline \multicolumn{6}{|l|}{ Sewers } \\
\hline Sewer operating costs (VSA 2011) & $\mathrm{cf}_{\text {sewerlifespan }}$ & $\$ \mathrm{~m}-1$ & 3.6 & & \\
\hline Sewer pipe lifespan (Maurer and Herlyn 2006) & $c f_{\text {sewer }}$ & $\mathrm{y}$ & 80 & 60 & 100 \\
\hline Sewer replacement value (A & & $\%$ & 0 & -20 & +20 \\
\hline \multicolumn{6}{|l|}{ Sewage pumps } \\
\hline Electricity costs (BFE 2011) & & $\$ \mathrm{kWh}^{-1}$ & 0.14 & & \\
\hline \multirow[t]{2}{*}{ Pumping operation cost function (Grundfos 2014) } & & $\mathrm{kWh}$ & Section & & \\
\hline & & & 2.2.4.2 & & \\
\hline \multicolumn{6}{|l|}{ WWTP } \\
\hline WWTP operating cost (VSA 2011) & $\mathrm{cf}_{\text {wwtpopex }}$ & $\%$ & 0 & -20 & +20 \\
\hline WWTP replacement value (VSA 2011) & $\mathrm{cf}_{\text {wwppapex }}$ & $\%$ & 0 & -20 & +20 \\
\hline WWTP lifespan (Maurer and Herlyn 2006) & $c f_{\text {wwtplifespan }}$ & y & 33 & 30 & 40 \\
\hline \multicolumn{6}{|l|}{ Other Parameters } \\
\hline Real interest rate (Maurer and Herlyn 2006) & $\mathrm{cf}_{\text {interest }}$ & $\%$ & 2 & 0 & 6 \\
\hline Reasonable costs ('A WEL 2005) & $\mathrm{cf}_{\mathrm{rc}}$ & $\$$ & 5357 & 0 & 14286 \\
\hline
\end{tabular}

Table 1: Cost and design-related model parameters. The considered standard pipe diameters are (in $\mathrm{m}$ ): $0.25 .0 .3,0.4,0.5$, $0.6,0.7,0.8,0.9 .1,1.2,1.5,2,2.5,3,4,6,8$.

defined in step III with the aid of the cost module (Section 2.2.4).

Step $V$ : The choice for one of the options designed in Step III is made by considering reasonable costs $\left(c f_{r c}\right)$. These costs are politically defined per capita cost values, which decide whether a decentralised option may be legally considered. Below that value, sewer connections are enforced. Similar criteria, such as distance measures, are used in many countries in what is known as the mandatory connection rule (e.g. Switzerland, Germany and Austria). 


\subsubsection{System Option Module (SOM)}

The SOM creates different system options on the basis of the two nodes considered for connection in each iteration of the EM. A local competitive choice is then made from these options on the basis of cost calculations relating to all system elements. The modelled system elements are gravity driven and pressurized sewage pipes and WWTP. See Table 1 for all parameters influencing the design of the sewage system.

In each iteration, only two nodes are considered for designing system alternatives: this results in three possible options (Fig. 2). For two of these, the two nodes are connected and the network is consequently expanded. The existing WWTP is then either enlarged (option A), or else abandoned and a new one is built in the new node (option C). Alternatively, the new node is not connected and serviced by a separate WWTP (option B).

\subsubsection{Merging Module (MM)}

In the second step of the algorithm (see lower part in Figure 1), the MM optimises the configuration found by the EM by merging WWTP based on agglomerative hierarchical clustering (HAC), where we consider each WWTP with the corresponding network as a cluster. The motivation to merge plants lies in the economies of scale achieved as the per capita treatment costs decrease with growing networks and consequently larger WWTP.

$\mathrm{HAC}$ is a distance-based bottom-up clustering algorithm in which each single object is treated as a cluster and then iteratively agglomerated until all objects are either merged or the algorithm is aborted on the basis of defined criteria (Manning et al. 2008). A typical property of HAC algorithms is that the number of clusters does not need to be defined a priori, which suits our need to find the optimal number of plants. The challenge of HAC methods is finding dissimilarity coefficients for cluster building. These coefficients reflect the dissimilarity between clusters and are often obtained from distance calculations or more complex computations (Kaufman and Rousseeuw 2005). For this study, we define the connection costs between WWTP as dissimilarities.

Because of the high calculation intensity of testing all merging possibilities or calculating the dissimilarity coefficients of all WWTP in each iteration, a heuristic selection of possible merges is made in the MM. The selection takes place in three major steps (compare Fig. 1):

Step I: As possible economies of scale can most probably be exploited by merging larg-

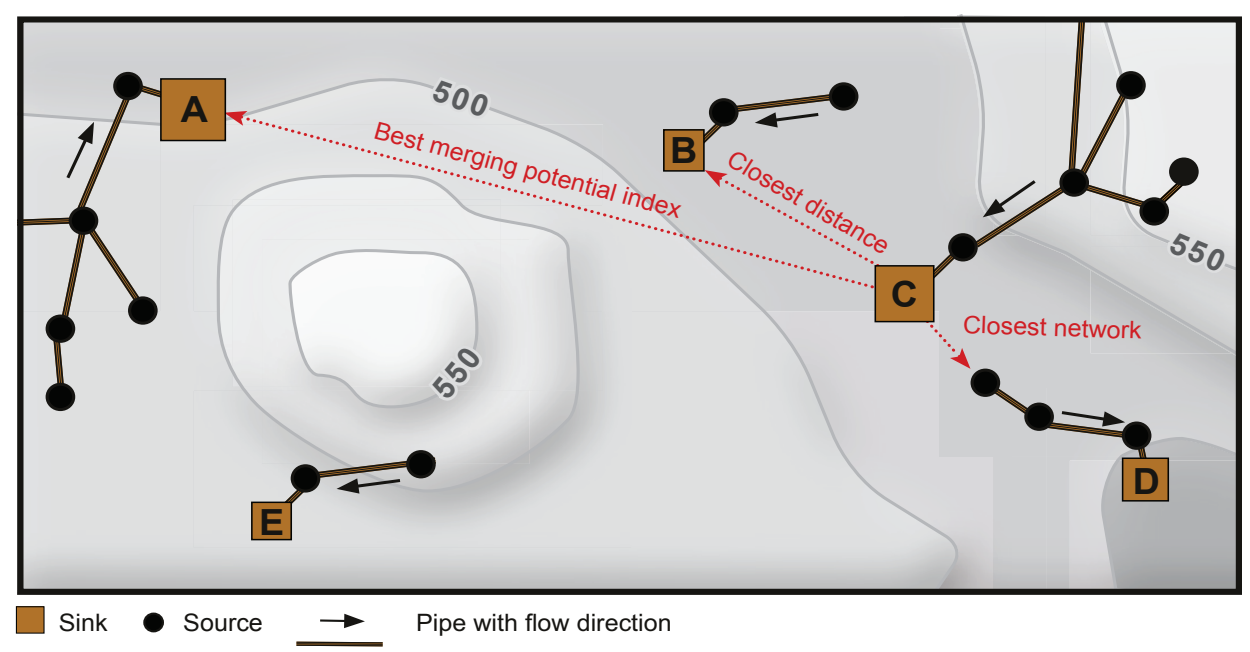

Figure 3: Exemplary representation of the WWTP selection by the SOM heuristic for WWTP C. B is closest to C, D has the closest network to $\mathrm{C}$ whereas $\mathrm{A}$ has the best merging potential for $\mathrm{C}$ due to its size (see Equation 4). 
er plants, each merge check is always started with the largest WWTP and is terminated as soon as all plants have been checked.

Step II: The three most promising WWTP to be considered for merging are determined with the aid of the SOM. The SOM finds the closest WWTP, the WWTP of the closest sewer network and the network with the highest merging potential $f_{\text {MergePot }}$. This potential is a distance-to-WWTP size ratio and is expressed as (Eq. 4)

$$
f_{\text {MergePot }}=d\left(W W T P_{\text {size }}\right)^{-f_{\text {merge }}}
$$

where $d$ is the distance between two nodes, fmerge the weighting factor and WWTP${ }_{\text {size }}$ the size of a WWTP given in population equivalents. The exponent fmerge allows us to increase the weighting for the size of the WWTP, thus decreasing the importance of the distance when choosing a WWTP to merge. This means that a higher merging potential is assigned to larger and more distant WWTP. We consider distance and size to be good criteria for selecting WWTP as the high cost of connecting more distant WWTP could be compensated thanks to economies of scale in wastewater treatment. Figure 3 explains the various possibilities of the SOM. Let us consider facility $\mathrm{C}$ in the illustrated example and determine the three WWTP to be checked for a merge. The closest facility is $\mathrm{B}$, the facility with the closest sewer D and the facility with the best merging potential index is $\mathrm{A}$ because of its larger size.

Step III: The WWTP identified in Step II are tested for a merge. The sewer path between two WWTP is derived from the PFM (IIIa), the sewage system options found (IIIc) and the costs calculated (IIId). In the process of finding interconnecting sewer paths between WWTP, other sewer networks may be crossed. In such cases, the intersected network elements are removed from the current network (IIIb) and are reconnected with the EM in case of reduced system costs.

\subsubsection{Cost Module (CM)}

The SNIP algorithm finds an optimal wastewater management configuration by minimizing operation and capital replacement costs, which are calculated with help of the CM. In order to compare the different costs, we calculate the total replacement costs and convert them to equivalent uniform annual cash flows or annuities. The annuities $A$ can be calculated from a net present value (NPV) written as (Eq. 5) ('Crundwell' 2008).

$$
A=N P V \frac{q^{n}(q-1)}{q^{n}-1}
$$

where $\mathrm{q}$ is the (real) interest rate +1 and $\mathrm{n}$ the number of years for depreciation. All local currencies are converted to US\$ using purchase power parities for the year 2013 (World Bank 2014). All cost factors used are listed in Table 1.

\section{Sewers}

As sewer construction costs depend on numerous factors, it is problematic to derive general costs. We reduce the cost factors to the trench depth, pipe diameter and sewage pipe length in accordance with a cost model from the case study area (AWA 2001) which relies on Swiss sewer construction standards. The sewage replacement costs $\mathrm{c}$ are calculated with the aid of the average trench depth $T_{a v g}$ and the cost coefficients $a$ and $b$ relating to the pipe diameter (Eq. 6):

$$
c=a T_{a v g}+b
$$

We calculate the sewer diameters using a standard engineering approach according to Manning-Strickler (compare for example Maurer et al. 2012). A maximum trench depth restriction $T D_{\max }$ prevents the construction of sewage pipes too deep underground. If the minimum slope restriction $\left(f_{\text {minslope }}\right)$ cannot be maintained 
because of $T D_{\text {max }}$, the wastewater is pumped. The parameter fminslope describes the slope of the sewers which need to be constructed in order to allow gravity-driven flow. Therefore $f_{\text {minslope }}$ does not represent the slope of the terrain. In case of steep terrain, the sewer slope is similar to the terrain slope. In flat terrain, the slope corresponds to the value given by $f_{\text {minslope }}$. Sewer operation costs are taken from the literature and set to average costs per metre per year (IVSA 2011) (see Appendix A).

\section{Pumps}

Wastewater is pumped wherever the topography does not provide enough downward gradients. We use a very simplified approach for calculating pumping costs. Given the genericness of the plain model design, we do not consider costs resulting from the need to provide pumping redundancy, potential wastewater storage costs for pump sumps, or cost differences depending on the pump size. Furthermore, we do not consider economies of scale, but only assign a fixed cost for a pumped volume. As a consequence, SNIP does not minimize the number of pumps but only the sewer length where pumping is required. Further SNIP generally neglects different kinds of implications such as odour problems or hygienic challenges resulting from long residence times.

We choose a methodology to estimate the needed power input $P_{g r}$ from a standard engineering sewage pumping handbook (for example 'Grundfos 2014) (Eq. 7):

$$
P g_{r}=\frac{g Q H}{n_{g r}{ }^{*} 1000}
$$

Pgr: motor power input [kW]

Q: pump volume flow at duty point [l/s]

H: pump head at duty point [m]

$g$ : gravitational constant $\left[\mathrm{m} / \mathrm{s}^{2}\right]$

$n_{g r}$ : overall energy conversion efficiency

The total cost of the energy consumption for one year is calculated by multiplying $P_{g r}$ with the running time per year and the specific average pumping costs.

\section{Wastewater treatment plants}

According to Friedler and Pisanty (2006), WWTP cost functions are best expressed by a power law (Eq. 8)

$$
c=a x b
$$

where the costs $c$ are estimated by defining $\mathrm{x}$ as the plant capacity in population equivalents and using the cost coefficients $a$ and $b$.

We found it challenging to determine a single generic cost function over the entire range of possible WWTP sizes. The available data indicate that smaller package treatment plants show a different cost scaling behaviour than the larger custom-built ones. The operating-cost and replacement-cost functions for the WWTP used in this paper are taken from 'VSA (2011)' derived from larger WWTP.
DC: 0

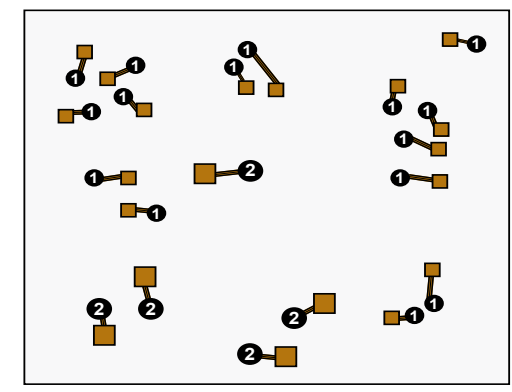

DC: 0.56

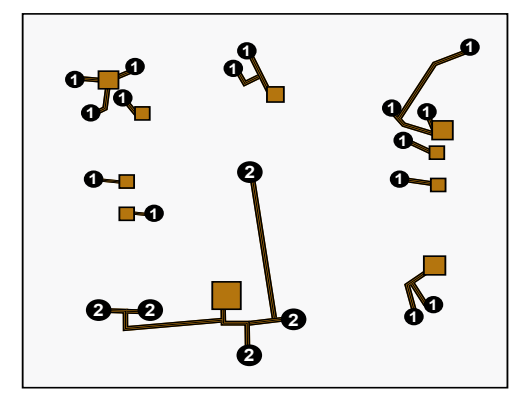

DC: 1

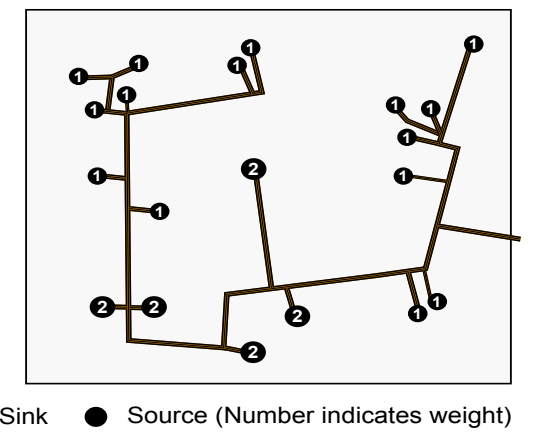

Figure 4: Example calculations of DC. The characteristic of DC can be seen in the situation in the middle, where on average two nodes are connected to a plant, but we calculate a value higher than 0.5 because of the merging of nodes with higher weights. 


\section{Materials and Methods}

T $\mathrm{n}$ order to test the adequacy of the SNIP al1 gorithm, we carried out the following analysis steps. First we defined the degree of centralisation. Second we determined the influence of SNIP variable changes with the aid of a sensitivity analysis in order to determine whether we could distinguish between important and less important variables. Third, we conducted a total of 250 model runs for different topographies in order to determine whether SNIP gives reasonable representations of possible WWTP and sewer outlays.

\subsection{Defining the Degree of Centralisation}

7 he current discussion about central or de1 central infrastructure planning is often fuzzy due to a lack of clear definitions. In practice, simple measures, such as the dimension (e.g. treated volume) or vague terms relating to the served area (e.g. small) or distance (e.g. close) are often used to define decentralised treatment plants (cf. Makropoulos and Butler 2010, DIN 4261 2010, 'EPA 2005, Cook et al. 2009). However, such a definition is problematic in two ways: first, the understanding of the terms "centralised" or "decentralised" depends on the chosen system boundaries, as we can define a continuum of different wastewater system scales (Hamilton et al. 2004). Second, the definition of the ODC is often limited to two categories: a source is either fully connected or entirely decentralised. Such a dichotomic definition of system alternatives is unrealistic as a whole range of intermediate solutions may be possible.

A more systematic definition taking into account the continuum of possible facility sizes is adapted from Ambros (1996) (Eq. 9):

$$
D C=\frac{\sum_{i=1}^{n} N_{i}-\sum_{j=1}^{m} \frac{M_{j}}{B_{j}}}{\sum_{i=1}^{n} N_{i}}
$$

where we define a weighted degree of centralisation (DC). For this paper, $\mathrm{M}$ denotes the volume of wastewater which needs to be treated at a sink (treatment plant), $N$ the volume of wastewater originating from a source (household) and $B$ the number of sources connected to a sink. We sum over all sources $(i=1, \ldots, n)$ and sinks $(j$ $=1, \ldots, m)$. Compared to the original definition, the DC allows us to consider different source weights, as the required wastewater quantity to be treated at the sources may differ. If $\mathrm{DC}$ is 0 , we find complete decentralisation with a sink placement at each source. If treatment takes place only outside the considered area, the DC reaches 1 (Fig. 4).

\subsection{Case Studies}

T $\mathrm{n}$ order to test SNIP under varying system conditions, we introduce virtual case studies (Section 3.2.1) and apply SNIP to a real-world case (Section 3.2.2). It is problematic to validate the model results with real world data because existing systems have grown historically and mostly constitute combined sewer systems. This means that even newly designed systems would look different. An advantage of the virtual case study approach is that we can easily generate and test SNIP for a broad set of different conditions. On the basis of the real world application, we can show the potential of SNIP for a given Swiss context in an exemplary way.

\subsubsection{Virtual Case Studies}

In order to better understand our algorithm, we generate contrasting virtual cases with real world topographies but virtual settlement distributions and use face validation to see whether the input-output relationships of the model are reasonable (Sargent 1991). The virtual case study allows us to observe whether the model can be sensibly applied in different contexts considering completely different topographies or settlement distributions. We use the ruggedness terrain index (RTI) (Riley et al. 1999) and the vector ruggedness measure (VRM) (Sappington 

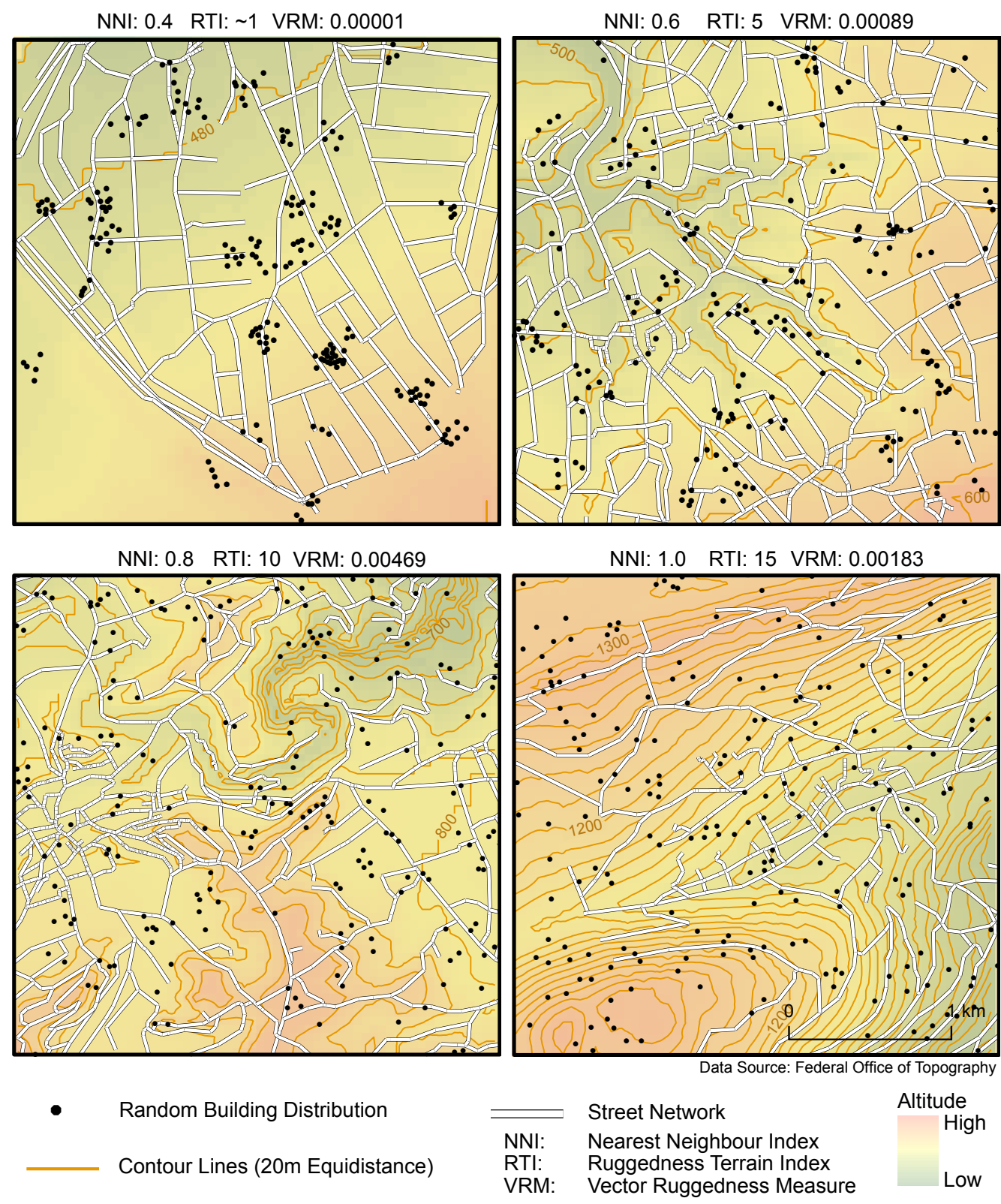

Figure 5: Overview of virtual case studies. A different exemplary settlement distribution is displayed for each topography. We use real world topography and street networks but redistribute the buildings in order to achieve a different source clustering.

'et al. 2007) to quantify terrain complexity, and the nearest neighbour index (NNI) ('Clark and Evans 1954) to quantify the degree of clustering of the inhabited buildings.

The virtual case studies (Fig. 5) are created as follows: we select four clippings (of $9 \mathrm{~km} 2 \mathrm{each}$ ) from the digital elevation model of Switzerland and the respective street networks. By calculating the RTI and VRM, we are able to select topographically contrasting cases. We then create different virtual settlement distributions (with 200 buildings) on the selected clippings with nearest neighbour indices ranging from 0.2 to 1 . We assume that the amount of wastewater flow is equal for each building.

\subsubsection{Real World Case Study}

The SNIP model was applied to the community of Trubschachen ( 1500 inhabitants, 365 buildings) in the Emmental region of western Switzerland. This region is hilly, relatively sparsely populated and makes network infrastructure planning challenging because of its complex topography and settlement distribution. Today's relatively high presence of on-site solutions in 
this region already indicates a borderline situation for the central network paradigm. Based on the current distribution of small WWTP and network outlay of Trubschachen, we calculate the actual DC as 0.85 .

We assign an average wastewater production to the number of people living in a building. Access to population distribution data on a high spatial scale is often problematic either because of missing data or due to privacy concerns. Therefore we spatially disaggregate the population with the aid of a dasymetric mapping technique developed by Lwin and Murayama (2009).

We run a variance-based sensitivity analysis in order to quantify the total effect of each parameter on the model output for the real world case study. The extended Fourier Amplitude Sensitivity Test (eFAST) of Saltelli et al. (1999) allows us to cope computationally with a large number of factors and take the interactions between them into account (Crosetto et al. 2000). The analysis is performed in $\mathrm{R}$ with the $\mathrm{R}$ package "sensitivity" of Pujol (2014). As there is no exact rule for finding an adequate sample size of eFAST, we use a number close to the minimum

\begin{tabular}{|c|c|c|c|}
\hline Parameter & Description & $\begin{array}{l}\text { Main } \\
\text { Effect }\end{array}$ & $\begin{array}{c}\text { Interaction } \\
\text { Effect }\end{array}$ \\
\hline$Q_{\mathrm{ww}}$ & Wastewater production & 0.0364 & 0.4390 \\
\hline$c_{\text {fwwtplifespan }}$ & WWTP lifespan & 0.0665 & 0.4928 \\
\hline $\mathrm{cf}_{\text {wwtpopex }}$ & WWTP replacement value & 0.0881 & 0.4104 \\
\hline $\mathrm{cf}_{\text {sewer }}$ & Sewer replacement value & 0.0884 & 0.5283 \\
\hline $\mathrm{cf}_{\text {sewerlifespan }}$ & Sewer pipe lifespan & 0.0886 & 0.4113 \\
\hline $\mathrm{cf}_{\text {interest }}$ & Real interest rate & 0.0973 & 0.8000 \\
\hline$f_{\text {topo }}$ & Sewer design factor & 0.0993 & 0.5585 \\
\hline$c f_{\text {wwtpcapex }}$ & WWTP replacement value & 0.1318 & 0.4111 \\
\hline$f_{\text {merge }}$ & Merging factor & 0.1518 & 0.6279 \\
\hline $\mathrm{T}_{\max }$ & Maximum trench depth & 0.1567 & 0.5760 \\
\hline $\mathrm{cf}_{\mathrm{rc}}$ & Reasonable cost & 0.1762 & 0.6142 \\
\hline$f_{\text {minslope }}$ & Sewer design factor & 0.1977 & 0.5927 \\
\hline$f_{\text {street }}$ & Sewer design factor & 0.3408 & 0.8657 \\
\hline
\end{tabular}

Table 2: eFAST results (sample size $=70$ ). See Table 1 for a more detailed description of the parameters. known value (Marino et al. 2008). For eFAST, we do not consider changing starting nodes and start with a node located in a densely populated area.

\subsection{Data and Software}

NIP was developed to be as economical as $\checkmark$ possible with regard to data requirements. All data are generally easily accessible and were obtained from the Swiss Federal Office of Topography (see Appendix C). SNIP is implemented in Python 2.7.3. ArcGIS ${ }^{\circledR} 10.2$ is used for reading and visualisation purposes.

\section{Results and Discussion}

\subsection{Sensitivity Analysis}

12 he result of the sensitivity analysis in Table sewer design factors have a predominantly greater effect on the ODC even though the differences between individual factors are generally not very distinct. The analysis shows that the sewer design factor fstreet (main effect of 0.34 ) that characterises when to follow the street and when to build sewers along the terrain has a particularly large impact on the ODC. This emphasises the importance of determining the relationship between the given street network and the sewer outlay for each case study. Similarly, other sewer-related design factors such as the minimal slope, $f_{\text {street }}$ (main effect of 0.20 ), or the maximum trench depth $\mathrm{T}_{\max }$ (main effect of 0.16 ) are also sensitive. The high general interaction effects of all parameters, indicating a high correlation between them, are not unexpected, as many of these parameters have a direct influence on costs, and thus to a change of DC. As many of these parameters relate to real-world characteristics, it is possible to treat them as input parameters and obtain sensible values for a given application case. As a consequence, only three 'real' model parameters remain, $f_{\text {topo }}, f_{\text {merge }}$, and $f_{\text {street }}$, all three of which are sensitive and correlated with other parameters. 


\subsection{Face Validation Virtual Case Studies}

W

e are testing the proposed SNIP algorithm in the four virtual case studies shown in Fig. 5. They differ with respect to terrain ruggedness and source clustering. We expect lower degrees of centralisation (lower DC values) wherever we encounter high terrain complexity and distributed sources due to higher network construction costs. We find this general pattern to be true for our virtual case studies. Figure 6 shows a very distinctive dependency of DC on the NNI. The effect of the terrain complexity is much less visible.

We notice that the DC does not always decline with increasing RTI values. Despite high RTI values due to large even flanks, such a topography favours gravity-driven sewer construction. This is reflected in the VRM index, which we use to distinguish steep even terrain from steep uneven terrain (Sappington et al. 2007). Therefore the choice of index matters when relating topographical complexity to DC.

\subsection{Real World Case Study}

TT $\mathrm{e}$ ran our algorithm for the community of Trubschachen and calculated an

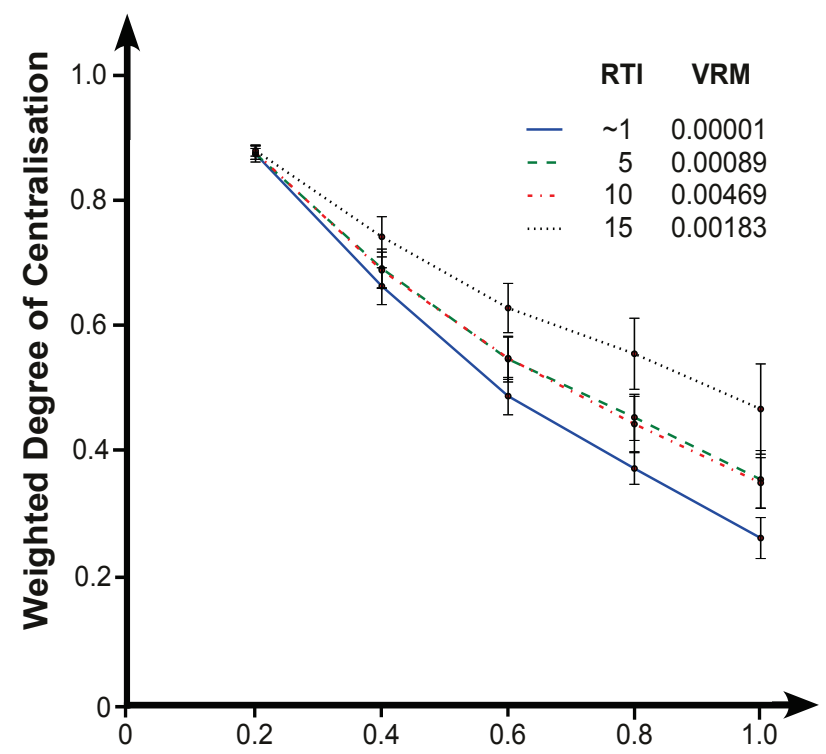

Figure 6: SNIP results for virtual case studies with different degrees of source clustering and different topographic complexities. We distributed 200 buildings and generated 50 model runs in each case. The error bars show the standard deviation of the 50 settlement distributions for each situation.
ODC of 0.76 (Appendix B). Figure 7 shows annuities for different $\mathrm{DC}$ for this catchment. We see that the overall costs decrease with increasing centralisation due to a decrease of WWTP costs and a relatively slow increase in sewerage costs. This is valid to the proposed optimal centralisation degree where $\mathrm{DC}=0.76$. After this, the costs for sewer lines and pumping costs exceed the economies of scale of the WWTP. We have extended the calculations of the total system costs represented in Fig. 7 beyond the ODC in order to illustrate the consequences of forced centralisation and as well as to allow a comparison with the actual degree of centralisation. The initial gradual decrease takes place in the EM whereas the cost drop at about 0.72 results from merging (agglomerating) WWTP within the MM. The increasing marginal sewer connection costs are particularly noticeable where DC is close to 1 , which shows the high costs of connecting the most remote settlements.

The calculated DC is lower than the effective centralisation achieved in Fig. 8. We observe that sewers follow the street network in the urban area more closely and deviate more for single rural buildings, which is plausible and corresponds to the real situation (compare Blumensaat et al. 2012). Figure 8 indicates that in reality more buildings were connected to the central system than the economically optimal number. In the real case, the implementation of sewer lines stopped only when pumping costs substantially increased. Visual inspection of Fig. 8 confirms that the two system settings differ mostly by quite remote settlements (blue sewers in Fig. 8).

Nonetheless, the difference between today's $\mathrm{DC}$ and the ODC fits well for Switzerland in general as well as for Trubschachen, whose wastewater infrastructure was largely built during the economic boom of the 1960s, 70s, and 80s, when on average $37 \%$ of wastewater evacuation costs was subsidized (Müller and Kramer 2000, Maurer and Herlyn 2006). Additionally, a lot of infra- 


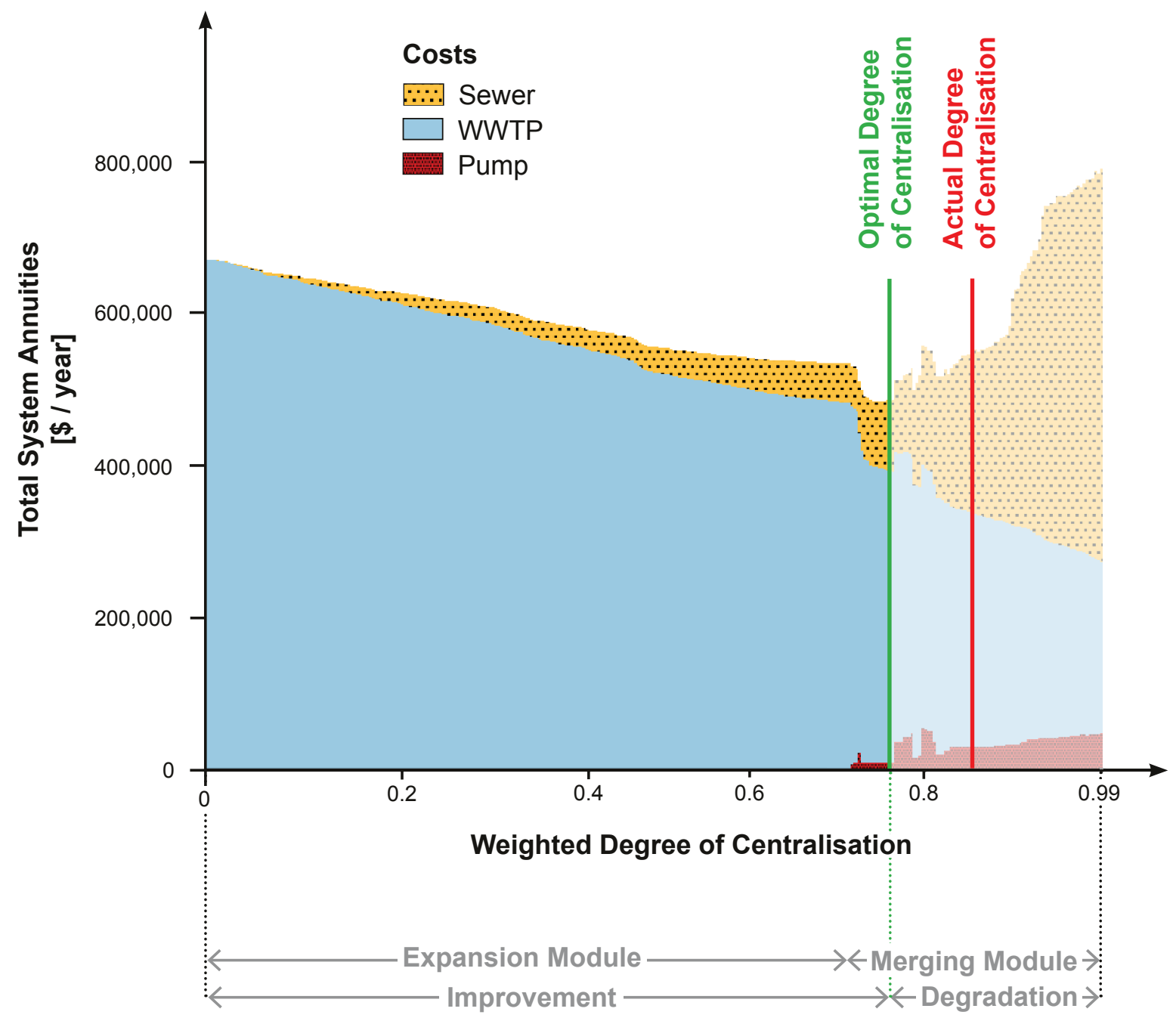

Figure 7: Total system annuities of Trubschachen as a function of DC. The cost shares of the different system elements shift with increasing DC from WWTP costs towards sewer and pumping costs until minimum total system costs are reached at $\mathrm{DC}=0.76$.

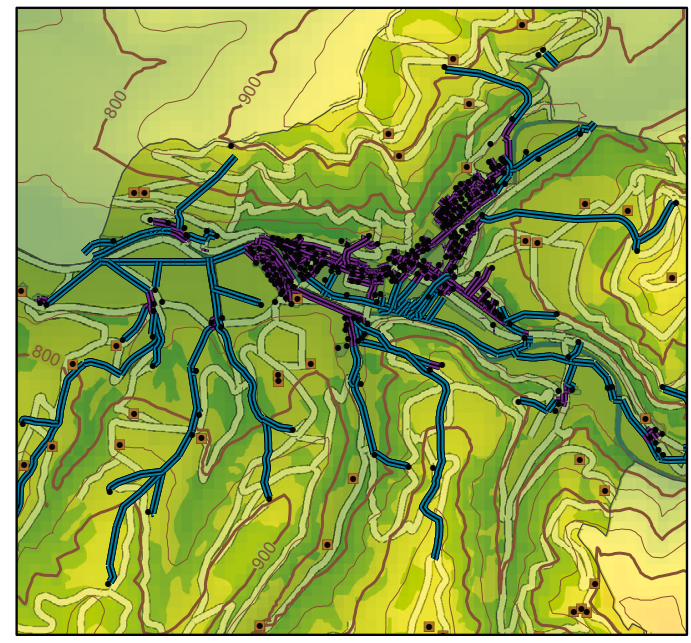

Sewer

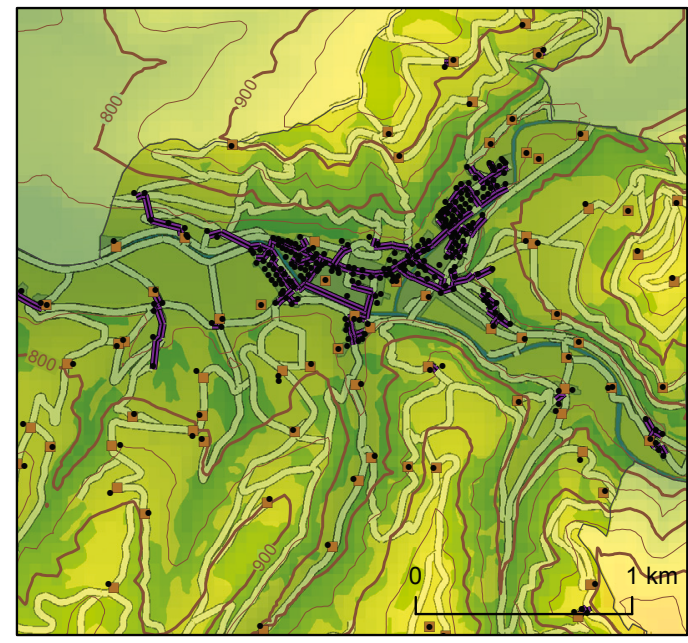

Data Source: Federal Office of Topography

Not optimal sewers $\quad$ - Building

$\square$ WWTP $\quad$ Street Network

Figure 8: Today's wastewater system connecting the inhabited buildings (left) and optimum system design calculated with SNIP using the base parameters (right). We assume that all inhabited buildings which are not connected to the sewers currently have an on-site treatment solution. 
structure was planned and built at a time when small treatment plants had a distinctly worse performance compared to large ones, which was the reason for the subsidies. So it is not surprising that today's network system is over-dimensioned from a cost efficiency point of view. We see that SNIP allows decision makers to re-asses the economic efficiency of a given system and to consider disconnecting certain households or at least delay rehabilitation projects until decentralised systems can be implemented.

\subsection{Limitations and Research Needs}

7 hese results highlight an important as1 pect of the SNIP approach, namely that it is a single-objective approach exclusively focussing on cost minimisation and thus ignores other performance or sustainability goals that a wastewater system could fulfil. An important assumption underlying the current approach is that all possible system configurations (from fully centralised to fully decentralised) achieve the same performance. There are good indications that this last strong assumption might become superseded by current research efforts on small-scale treatment systems (see also Larsen et al. 2013).

Other important limitations of the SNIP approach are:

- The presented cases contained only foul sewers. For storm sewers, it is less a question of treatment than of transportation, and is dealt with in the literature (inter alia Urich et al. 2013, Bach et al. 2014). Expanding SNIP with combined sewers is fairly simple, as it only requires the design rain input for each source and the identification of suitable combined sewer overflow points.

- It does not consider the currently existing network infrastructure. SNIP provides a pseudo- or quasi optimal situation for a given catchment, ignoring any transition scenarios needed to transform an existing infrastructure.

- SNIP is static, ignoring dynamic changes in settlement patterns or changing input parameters. The results for the presented case studies show that changing settlement structures are of particularly great importance for the ODC.

The last two points (transitions and scenario planning) in particular need to be addressed if SNIP is to serve as a more realistic planning tool. It is important to realise that SNIP cannot currently be seen as a prescriptive tool for system implementation, but more as a form of guidance about the momentary sensible extent of the network infrastructure. SNIP can contribute an additional perspective in a system planning process by providing cost-effective alternatives. We believe that SNIP not only has value for planning new infrastructure but also in guiding or stimulating infrastructure transitions for existing sewer networks. This is increasingly important in contexts where major investments need to be made in existing infrastructures.

Additionally, more research is needed to determine better cost functions depending on the particular case study. Whereas we consider model uncertainty as a minor problem, the standard deviation of our random distribution in Fig. 6 and the starting node uncertainty in Fig. B.1 indicate that different results may be obtained depending on the chosen input parameters. But we argue that such uncertainty could even serve as a valuable input for a planning process.

There are a number of other ways in which the SNIP approach may be further developed. We especially see potential in broadening the set of criteria to address the sustainability of network infrastructure planning in a holistic way. 


\section{Conclusions}

W

e present the heuristic SNIP algorithm as a tool to model the optimal degree of centralisation (ODC) for wastewater infrastructures. We consider the optimal number, placement and sizing of wastewater treatment facilities, gravity-driven and pressurised sewer networks as a fixed-charge location problem and use heuristics to find cost-minimised solutions.

SNIP is generic and uses only basic data input, thus allowing easy transfer to other case studies. We find that the SNIP algorithm can generate interesting plausible suggestions for sewer networks on a small scale and also produce face-value plausibility in virtual case studies. In-depth analyses will need to follow in the event of possible implementation. The approach presented here considers economies of scale, calculates costs depending on network position and considers the influence of the topography on sewer design when addressing the question of ODC. Most importantly, it takes into account different sizes of treatment plants and is applicable to local scale analysis. It also allows us to go beyond the often fruitless discussion about the appropriateness of on-site versus fully centralised solutions. Moreover, the combination of quantitative measures for settlement distribution and topographic complexity used for the calculated ODC allows us to quickly derive estimates of the ODC for different case studies. The real-world application of SNIP to a Swiss community suggests that the prevailing sewer system is over-centralised. Thus the SNIPODC may guide decision-makers to ask the right questions about the cost-efficiency of the current infrastructure layout and demonstrates that questions relating to current planning approaches need to be addressed in more detail. Knowing the ODC represents valuable infor- mation, especially in those cases in which new infrastructure needs to be built or already built infrastructure has to be redeveloped.

SNIP is based on heuristics, so the ODC solutions found are (pseudo-) optimal with regard to a rather restricted set of criteria. Even though its artificially generated wastewater systems are based on real world sewer-design principles, our model in no way replaces detailed engineering decisions on the ground. SNIP depends on generic design and cost parameters, and in combination with the model uncertainty it is obvious that DC values obtained can only be approximate.

The application of tools such as SNIP is especially promising in the context of changing futures such as changing settlement patterns and shrinking or growing populations. SNIP has so far been applied on a local scale and needs to be extended to a regional scale. We believe that further improvement of our static one-dimensional optimisation process towards a multi-objective framework taking into account different context conditions will deliver insights into a possible sustainability transition (Coenen and Truffer 2012).

\section{Acknowledgements}

We thank Christoph Egger for his support with the cluster calculations and Andreas Scheidegger for his help with the sensitivity analysis. We are grateful for general advice from Robert Weibel. We also thank Ruefer Ingenieure AG for providing their data and Richard Michell for proof reading. Furthermore, we are grateful for the fruitful feedback from our three anonymous reviewers.

\section{Source Code}

The source code and an ArcGIS-Toolbox are available from: https://github.com/eggimasv/SNIP 
Appendix A

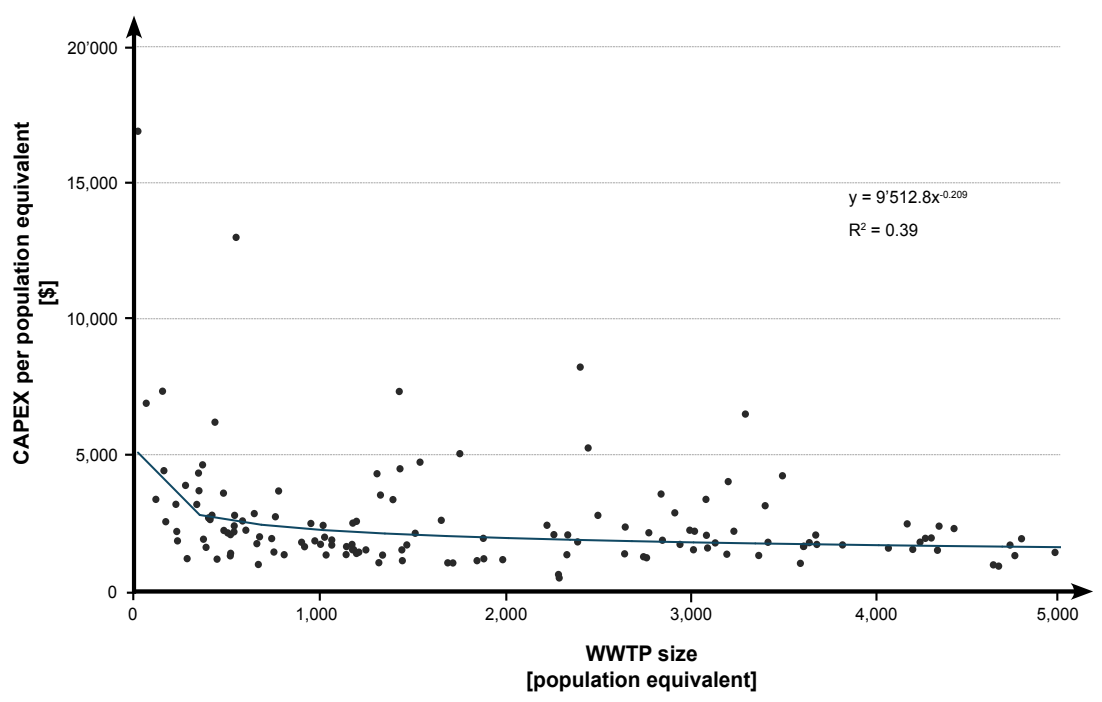

Figure A.1: WWTP capital expenditure cost curve from VSA (2011).

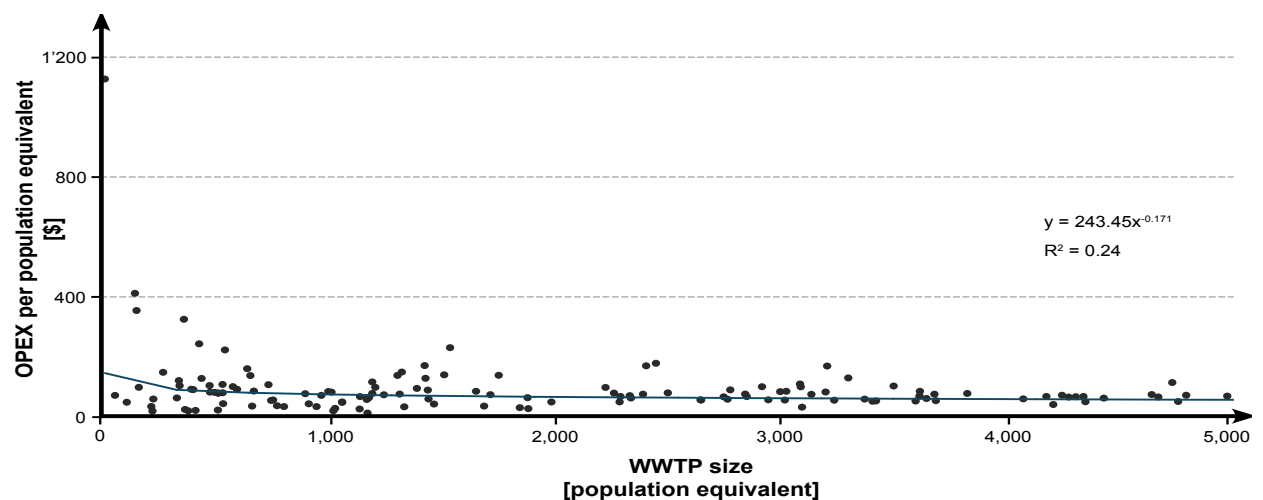

Figure A.2: WWTP operation expenditure cost curve from VSA (2011).

\section{Appendix B}

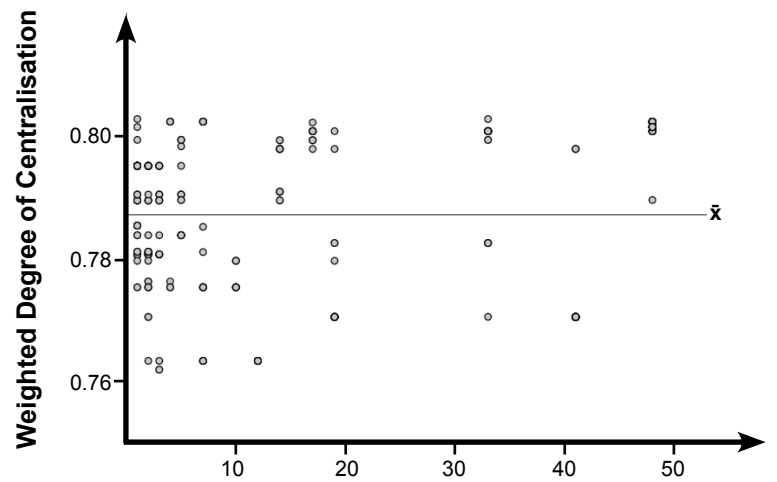

Figure B.1: Case study results for Trubschachen. We run SNIP from each start node $(\mathrm{n}=362)$, which results in a $\mathrm{DC}$ ranging from 0.76 to $0.80(\overline{\mathrm{x}}=0.787, \sigma=0.01)$

\section{Appendix C}

\begin{tabular}{lll}
\hline Data & Description & Source \\
\hline Digital terrain model with & Raster & swisstopo \\
a resolution of $25 \mathrm{~m} \mathrm{x} 25 \mathrm{~m}$ & & \\
Population data on community level & - & swisstopo \\
Street network & Vector & swisstopo \\
Buildings & Vector & swisstopo \\
\hline
\end{tabular}

Table C.1: Data sets used for SNIP.

\section{References}

AmbRos, R., 1996. Application of mathematical optimization methods for variant calculations (Anwendung mathematischer Optimierungsmethoden in der Variantenrechnung). Wiener Mitteilungen, Band 130, 107-133 (in German).

AWA, 2001. Approach for calculating costs of sewers (Vorgehen zur Bestimmung der Kosten von Abwasserkanälen), Amt für Abwasser und Abfall des Kantons Bern, Bern, Switzerland (in German).

AWEL, 2005. AWEL. Guidelines concerning mandatory connection of property to the private and public sewerage system (AWEL-Richtlinien betreffend die Anschlusspflicht von Liegenschaften an die private und öffentliche Kanalisation.) Accessed: 05.05.2015 Archived by WebCite ${ }^{\circledR}$ http://www.webcitation. org/6YIKrL8cV (in German).

BACH, P. M., MCCARThY, D. T., URICH, C., SitZENFREI, R., KLEIDORFER, M., RAUCH, $W$., DELETIC, A., 2013. A planning algorithm for quantifying decentralised water management opportunities in urban environments. Water Science and Technology 68 (8), 1857-1865.

BACH, P. M., RAUCH, W., MiKKELSEN, P. S., MCCARTHY, D. T., DeLETIC, A., 2014. A critical review of integrated urban water modelling - Urban drainage and beyond. Environmental Modelling \& Software, 54, 88-107. 
BAufumÉ, S., GRÜGER, F., GRUbE, T., KROEG, D., LinsSEN, J., Weber, M., HAKe, J.-F., STOLTEN, D., 2013. GISbased scenario calculations for a nationwide German hydrogen pipeline infrastructure. International Journal of Hydrogen Energy 38 (10), 3813-3829.

$B F E, 2011$. Development of the Swiss electricity price (Strompreisentwicklung in der Schweiz). Neuchâtel, Switzerland (in German).

Blumensaat, F., Wolfram, M., Krebs, P., 2012. Sewer model development under minimum data requirements. Environmental Earth Sciences 65 (5), 1427-1437.

Brand, N., Ostfeld, A., 2011. Optimal Design of Regional Wastewater Pipelines and Treatment Plant Systems. Water Environment Research 83 (1), 53-64.

CLARK, P.J, Evans, F. C., 1954. Distance to Nearest Neighbor as a Measure of Spatial Relationships in Populations. Ecological Society of America 35 (4), 445-453.

Coenen, L., Truffer, B., 2012. Places and Spaces of Sustainability Transitions: Geographical Contributions to an Emerging Research and Policy Field. European Planning Studies 20 (3), 367-374.

Cook, S., TJandraAtmadja, G., Ho, A., Sharma , A., 2009. Definition of Decentralised Systems in the South East Queensland Context. Urban Water Security Research Alliance, Technical Report No. 12. City East, Australia.

Converse, A. O., 1972. Optimum number and location of treatment plants. Water Pollution Control Federation 44 (8), 1629-1636.

Cormen, T. H., Leiserson, C. E., Rivest, R. L., Stein, C., 2009. Introduction to Algorithms. MIT Press, Cambridge, Massachusetts, London, UK.

Crosetto, M., Tarantola, S., Saltelli A., 2000. Sensitivity and uncertainty analysis in spatial modelling based on GIS. Agriculture, Ecosystems and Environment $81,71-79$.

CRUNDWELL, F.K., 2008. Finance for Engineers. Evaluation and Funding of Capital Projects. Springer, London, UK.

Current, J., Daskin, M., SChilling, D., 2002. Discrete network location models. Chapter 3. In: Drezner, Z., Hamacher, H. (eds), Facility Location Theory: Applications and Methods, Springer-Verlag, Berlin, 81-118.

DASKIN, M. S., 1995. Network and discrete location models. In: Algorithms and Applications, Wiley, New York, USA.

Deichmann, U., Meisner, C., Murray, S., Wheeler, D., 2011. The economics of renewable energy expansion in rural Sub-Saharan Africa. Energy Policy 39 (1), 215-227.

DIJKSTRA, E. W., 1959. A note on two problems in connexion with graphs. Numerische Mathematik 1, 269-271.

DIN 4261, 2010. Small sewage treatment plants, English Version of DIN 4261:2010-10. DIN, Germany.

DownING, P. B., 1969. The economics of urban sewage disposal. Praeger, New York, USA.
EPA, 2005. Handbook for Managing Onsite and Clustered (Decentralized) Wastewater Treatment Systems. Environmental Protection Agency. Cincinnati, United States.

FriedLeR, E., PISANTY, E., 2006. Effects of design flow and treatment level on construction and operation costs of municipal wastewater treatment plants and their implications on policy making. Water Research 40,3751-3758.

GAREY, M. R., Johnson, D. S., 1979. Computers and Intractability: A Guide to the Theory of NP-Completeness. W. H. Freeman \& Co. New York, NY, USA.

GAwad, H., ButTer, J., 1995. Clustering of towns and villages for centralized wastewater treatment. Water Science and Technology 32 (11), 85-95.

GEELS, F. W., 2006. The hygienic transition from cesspools to sewer systems (1840-1930): The dynamics of regime transformation. Research Policy 25, 1069-1082.

GILs, H. C., Cofala, J., WAGNer, F., SCHÖPP, W., 2013. GIS-based assessment of the district heating potential in the USA. Energy 58, 318-329.

Gochenour, C., 2001. District energy, trends, issues, and opportunities. The Role of the World Bank. World Bank Technical Paper No. 493. Washington, D.C., USA.

GRAHAM, S., MARVIN, S., 2001. Splintering urbanism: Networked infrastructures, technological mobilites and the Urban Condition. Routledge, London, UK.

GRUNDFOS (EDS) 2014: The sewage pumping handbook: Grundfos wastewater. Accessed at: 30.04.2015. Archived by WebCite ${ }^{\circledR}$ http://www.webcitation. org/6YB8zRK65

HART, P. E., NiLSSON, N. J., RAPHAEL, B., 1968. A Formal Basis for the Heuristic Determination of Minimum Cost Paths. IEEE Transactions on Systems Science and Cybernetics SSC4 (2), 100-107.

Hamilton, B.A., Pinkham, R.D., Hurley, E., Watkins, K., Lovins, A.B., Magliaro, J., EtNier, C., Nelson, $V$., 2004. Valuing Decentralized Wastewater Technologies: a Catalog of Benefits Costs and Economic Analysis Techniques. Rocky Mountain Institute, Snowmass, USA.

HAWKEY, D. J. C., 2012. District heating in the UK: A technological innovation systems analysis. Environmental Innovation and Societal Transitions 5, 19-32.

HuGHES, T. P., 1983. Networks of power: electrification in western society, 1880-1930. JHU Press, London, UK.

JoHNSON, N., YANG, C., OGDEN, J., 2008. A GIS-based assessment of coal-based hydrogen infrastructure deployment in the state of Ohio. International Journal of Hydrogen Energy 33 (20), 5287-5303.

Kaufman, L., Rousseeuw, P. J., 2005. Finding Groups in Data. An Introduction to Cluster Analysis. An Introduction to Cluster Analysis, John Wiley \& Sons, Hoboken, NJ, USA.

KOCAMAN, A.S., HUH, W.T., MODI, V., 2012. Initial layout of power distribution systems for rural electrification: A heuristic algorithm for multilevel network design. Applied Energy 96, 302-315. 
LARSEN, T. A., UDERT, K. M., LieneRT, J., 2013. Source Separation and Decentralization for Wastewater Management. IWA Publishing, London, UK.

Leitão, J. P., Matos, J. S., Gonçalves, A. B., Matos, J. L., 2005. Contribution of Geographic Information Systems and location models to planning of wastewater systems. Water Science and Technology 52 (3), 1-8.

LEVIN, T., THOMAS, V. M., 2012. Least-cost network evaluation of centralized and decentralized contributions to global electrification. Energy Policy 41, 286-302.

Libralato, G., Ghirardini A. V., Avezzì, F., 2012. To centralise or to decentralise: An overview of the most recent trends in wastewater treatment management. Journal of Environmental Management 94, 61-68.

Lofrano, G., BROWN, J., 2010. Wastewater management through the ages: A history of mankind. Science of the Total Environment 408, 5254-5264.

Lwin, K., Murayama, Y., 2009. A GIS Approach to Estimation of Building Population for Micro-spatial Analysis. Transactions in GIS 13 (4), 401-414.

Makropoulos, C. K., Butler, D., 2010. Distributed Water Infrastructure for Sustainable Communities. Water Resources Management, 24 (11), 2795-2816.

Manning, C. D., Raghavan, P., Schütze, H., 2008. Introduction to Information Retrieval. University Press, Cambridge, UK.

Marino, S., Hogue, I.B., RAY, C.J., Kirschner, D. E., 2008. A methodology for performing global uncertainty and sensitivity analysis in systems biology. Journal of Theoretical Biology 254, 178-196.

MARLOW, D.R., MoGLIA, M., COOK, S., BEALE, D.J., 2013: Towards sustainable urban water management: A critical reassessment. Water Research 47, 7150-7161.

MaURER, M., Herlyn, A. 2006. Status, costs and investment needs of wastewater removal in Switzerland (Zustand, Kosten und Investitionsbedarf der schweizerischen Abwasserentsorgung). Eawag, Zurich, Switzerland (in German).

MAurer, M., Rothenberger, D., LARSEN, T.A., 2006. Decentralised wastewater treatment technologies from a national perspective: at what cost are they competitive? Water Science and Technology 5 (6) 145-154.

Maurer, M., ScheidegGer, A., Herlyn, A., 2012. Quantifying costs and lengths of urban drainage systems with a simple static sewer infrastructure model. Urban Water Journal, 1-13.

MölleR, B., Lund, H., 2010. Conversion of individual natural gas to district heating: Geographical studies of supply costs and consequences for the Danish energy system. Applied Energy 87, 1846-1857.

Moss, T., 2001. Flow management in urban regions. In: Guy S., Marvin, S., Moss, T. (eds), Urban infrastructure in transition, Earthscan, London, UK.

MÜlLER, A., KRAMER, D., 2000. Market economic instruments of sewage disposal (Marktwirtschaftliche Instrumente in der Abwasserentsorgung). Ecoplan. Bern, Switzerland (in German).
NIELSEN, S., MöLLER, B., 2013. GIS based analysis of future district heating potential in Denmark. Energy $57,458-468$.

OECD, 2006. Infrastructure to 2030: Telecom, Land Transport, Water and Electricity. OECD Publishing, Paris, France.

OECD, 2007: Infrastructure to 2030 (Volume 2): Mapping Policy for Electricity, Water and Transport, OECD Publishing, Paris, France.

OstFeld, A., 2015. Water Distribution Networks. In: E. Kyriakides and M. Polycarpou (eds.), Intelligent Monitoring, Control, and Security of Critical Infrastructure Systems, Studies in Computational Intelligence 565, Springer-Verlag, Berlin and Heidelberg, Germany.

Parshall, L., Pillai, D., Mohan, S., Sanoh, A., Modi, $V$., 2009. National electricity planning in settings with low pre-existing grid coverage: Development of a spatial model and case study of Kenya. Energy Policy 37 (6), 2395-2410.

Poustie, M. S, Deletic, A., BRown R. R., Wong, T., J. DE HAAN, R., SKINNER, R., 2014. Sustainable urban water futures in developing countries: the centralised, decentralised or hybrid dilemma. Urban Water Journal, 1-16.

PRIM, R. C., 1957. Shortest connection networks and some generalizations. Bell System Technical Journal, 36, 1389-1401.

PUJOL, G., 2014. Package 'sensitivity', Version 1.7. Available from: http://cran.r-project.org/.

RILEY, S. J., DEGLORIA, S. D., ELLIOT R., 1999. A terrain ruggedness index that quantifies topographic heterogeneity. Intermountain Journal of Sciences 5 (1-4), 23-27.

Rodrigue, J. P., ComtoIs, C., SLACK, B., 2013. The geography of transport systems. 3rd ed. Routledge, London, UK.

Saltelli, A., Tarantola, S., Chan, K. P. S., 1999. A quantitative model-independent method for global sensitivity analysis of model output. Technometrics 41, 39-56.

SANoh, A., PARshall, L., SarR, O.F., Kum, S., Modi, V., 2012. Local and national electricity planning in Senegal: Scenarios and policies. Energy for Sustainable Development 16 (1), 13-25.

SAPKOTA, M., ARoRA, M., MALANo, H., GEORGE, B., NAWARathNA, B., Sharma, A., Moglia, M., 2013. Development of a framework to evaluate the hybrid water supply systems. 20th International Congress on Modelling and Simulation, Adelaide, Australia, 1-6 December.

SAPKotA, M., ARoRA, M., MALANO, H., MogLIA, M., SHARmA, A., George, B., PAMminger, F., 2015. An Overview of Hybrid Water Supply Systems in the Context of Urban Water Management: Challenges and Opportunities. Water, 7(1), 153-174.

SAppington, J. M., Longshore, K. M, Thompson, D. B., 2007. Quantifying landscape ruggedness for animal habitat analysis: A case study using bighorn sheep in the Mojave desert. The Journal of Wildlife Management 17 (5), 1419-1426. 
SARGENT, G. R., 1991. Simulation model verification and validation. Proceedings of the 1991 Winter Simulation Conference.

SCHILLER, G., 2010. Cost evaluation of the adaptation of waste water treatment systems under shrinkage (Kostenbewertung der Anpassung zentraler Abwasserentsorgungssysteme bei Bevölkerungsrückgang). IÖR Schriften, Band 51. Rhombos, Berlin, Germany (in German).

SitzenfreI, R., MöDERL, M., RAUCH, W., 2013. Assessing the impact of transitions from centralised to decentralised water solutions on existing infrastructures e Integrated city-scale analysis with VIBe. Water Research 47, 7251-7263.

SitzenfReI, R., RAUCH, W., 2014. Integrated hydraulic modelling of water supply and urban drainage networks for assessment of decentralized options. Water Science \& Technology, 70 (11), 1817.

STILLER, C., BÜNGER, U., MøLLER-HOLST, S., SVENSSON, A.M., Espegren, A., NowaK, M., 2010. Pathways to a hydrogen fuel infrastructure in Norway. International Journal of Hydrogen Energy 35 (7), 2597-2601.

Tchobanoglous, G., LeVERENZ, H., 2013. The rationale for decentralization of wastewater infrastructure. In: Source Separation and Decentralization for Wastewater Management, Larsen, T. A., Udert, K. M., Lienert, J. (eds), IWA Publishing, London, UK.

UNEP 2015, Wastewater characteristics. Section 7.1.1 Wastewater Generation. Accessed: 30.04.2015. Archived by WebCite ${ }^{\circledR}$ http://www.webcitation. org/6YB8j1ifN

URBAN LAND INSTITUTE AND ERNST E YOUNG (EDS), 2007. Infrastructure 2007: A Global Perspective. ULI - the Urban Land Institute, Washington, D.C., USA.

URICH, C., Sitzenfrei, R., MöDERL, M., RAUCH, W., 2010. An agent-based approach for generating virtual sewer systems. Water science and technology: a journal of the International Association on Water Pollution Research 62 (5), 1090-1097.

URICH, C., BACH, P. M., SITZENFreI, R., KLEIDORFER, M., MCGARThY, D. T., Deletic, A., RAUCH, W., 2013. Modelling cities and water infrastructure dynamics. Engineering Sustainability 166 (ES5), 301-308.

URICH, C., RAUCH, W., 2014. Exploring critical pathways for urban water management to identify robust strategies under deep uncertainties. Water Research (66), 374-389.

VSA 2011: Costs and performances of the sewage disposal (Kosten und Leistungen der Abwasserentsorgung). Verband Schweizer Abwasser- und Gewässerschutzfachleute. Glattbrugg, Switzerland (in German).

Weber, B., Cornel, P., WAGNer, M., 2007. Semi-centralised supply and treatment systems for (fast growing) urban areas. Water Science \& Technology 55 (1-2), 349-356.

WORLD BANK (2014): PPP conversion factor. International Comparison Program database. Available at: http://data.worldbank.org/

YU, C., LEE, J., MunRo-STasiuK, M. J., 2003. Extensions to least-cost path algorithms for roadway planning. Geographical Information Science 17 (4), 361-376.

ZAHN, C.T., 1971. Graph-theoretical methods for detecting and describing gestalt clusters. IEEE Transactions on computers C-20 (1), 68-86.

Zeferino, J. A., ANTUNES, A. P., CunHA, M. C., 2010. Multi-objective model for regional wastewater systems planning. Civil Engineering and Environmental Systems 27 (2), 95-106.

Zvoleff, A., Kochman, A.S., HuH, W.T., Modi, V., 2009. The impact of geography on energy infrastructure costs. Energy Policy 37 (10), 4066-4078. 